\title{
Investigation of metallic nanoparticle distribution in PAN/magnetic nanocomposites fabricated with needleless electrospinning technique
}

\author{
Marah Trabelsi ${ }^{1,2,3}$, Al Mamun ${ }^{1,2}$, Michaela Klöcker ${ }^{2}$, Lilia Sabantina ${ }^{1,2}$ \\ 1 Junior Research Group "Nanomaterials”, Bielefeld University of Applied Sciences, 33619 Bielefeld, Germany \\ 2 Faculty of Engineering and Mathematics, Bielefeld University of Applied Sciences, 33619 Bielefeld, Germany \\ ${ }^{3}$ Ecole Nationale d'Ingénieurs de Sfax, Sfax 3038, Tunisia \\ *Corresponding author E-mail address: lilia.sabantina@fh-bielefeld.de
}

\begin{abstract}
INFO
CDAPT, ISSN 2701-939X

Peer reviewed article

2021, Vol. 2, No. 1, pp. 8-17

DOI 10.25367/cdatp.2021.2.p8-17

Received: 12 December 2020

Accepted: 18 February 2021

Available online: 26 February 2021

ABSTRACT

Needleless electrospinning can be used to produce, for example, poly(acrylonitrile) (PAN) nanofibers, to which magnetic nanoparticles can additionally be added. Such composite nanofibers can then be stabilized and carbonized to produce carbon composite nanofibers. The magnetic nanoparticles have an influence not only on the structure, but also on the mechanical and electrical properties of the finished carbon nanofibers, as does the heat treatment during stabilization and incipient carbonization. The present study reports on the fabrication, heat treatment and resulting properties of PAN/magnetic nanofiber mats prepared by needleless electrospinning from polymer solutions. A variety of microscopic and thermal characterization methods were used to investigate in detail the chemical and morphological transition during oxidative stabilization $\left(280{ }^{\circ} \mathrm{C}\right)$ and incipient carbonization $\left(500{ }^{\circ} \mathrm{C}\right)$. PAN and PAN/magnetic nanofiber mats were analyzed during all stages of heat treatment. Compared to pure PAN nanofibers, the PAN/magnetic nanofibers showed larger fiber diameters and the presence of beads and agglomerations. In this study, magnetic nanofibers were investigated in more detail with the aim of detecting undesired agglomerations. Visual observation, for example with confocal laser scanning microscopy (CLSM) or scanning electron microscopy (SEM), does not provide conclusive evidence of agglomerations in the nanofibers. But based on the capabilities of energy-dispersive $X$-ray spectroscopy (EDS), many different types of samples can be easily analyzed where other analytical techniques cannot give a fast answer.
\end{abstract}

\section{Keywords}

Needleless electrospinning,

magnetic nanofibers,

carbon nanocomposites,

agglomerations
(C) 2021 The authors. Published by CDAPT.

This is an open access article under the CC BY-NC-ND license https://creativecommons.org/licenses/ peer-review under responsibility of the scientific committee of the CDAPT. 


\section{Introduction}

The electrospinning technique is characterized by simplicity of use, versatility and adaptability $[1,2]$. Many variants of the electrospinning technique such as needleless and needle-based, melt, solvent and emulsion electrospinning, coaxial and co-electrospinning are known. A wide range of nano-architectures can be created using these electrospinning techniques, such as core-shell, tube-in-tube, porous, hollow, cross-linked and particle-encapsulated nanofibers [3-6]. The main components of a typical needle-based electrospinning system consist of a high-voltage power supply, a spinneret and a grounded collector plate [7-8]. Over time, needleless electrospinning has evolved into an alternative electrospinning technology with the aim of realizing large-scale nanofiber mats. There are also needleless electrospinning processes in which nanofibers are produced directly from an open liquid surface $[9,10]$. Poly(acrylonitrile) (PAN) is often used for the production of nanofibers because this polymer is relatively easy to handle and carbon nanofibers can be produced from it by heat treatment. Its carbon yield is relatively high which is advantageous for the production of carbon nanofibers [11].

The solvents in which PAN can be dissolved are polar solvents such as dimethylformamide (DMF) [12], dimethyl sulfoxide (DMSO) [13], dimethylacetamide (DMAc) [14], dimethyl sulfone, tetramethyl sulfide, and aqueous solutions of ethylene carbonate and some mineral salts $[15,16]$. This makes PAN very useful for a wide range of different applications [17,18]. According to scientific literature, most of the nanofibers are spun from toxic solvents such as DMF and DMAc [19], and only some papers report the use of the low-toxic solvent DMSO [20]. One of the advantages of PAN is its water resistance, which distinguishes it from other polymers [21]. In general, nanofiber mats can be used in a variety of fields, e.g., as filter materials [22,23], catalysts [24,25], cell growth, tissue engineering, medical dressings [2628]. Furthermore, PAN is a typical precursor for the production of carbon nanofibers [29].

Through thermal processing, carbon nanofibers can be produced from PAN nanofiber mats in a twostage process [30]. The first stage involves oxidative stabilization and it is an important heat treatment process to make the final yield of carbon material as large as possible. During oxidative stabilization, the PAN chains begin to cross-link. The resulting composite polymeric structure has the ability to withstand the rigors of high temperature processing in carbonization process more stably [31-33]. This process is crucial to prevent melting or fusing of the fibers. Another way to prevent nanofiber contraction during stabilization is electrospinning on metallic substrates [34]. Due to the conductivity of the metallic substrate, the nanofibers adhere to the surface and cannot shrink [35]. The oxidative stabilization reduces the volatilization of elemental carbon through the carbonization step and increases the final carbon yield. The process of carbonization helps in the formation of solid residues with increasing content of elemental carbon from organic material. The carbonization process is usually carried out in an inert gas, argon or nitrogen. Carbonization is a complex process in which dehydrogenation, condensation, hydrogen transfer and isomerization take place simultaneously [36]. The final pyrolysis temperature applied controls the degree of carbonization and the residual content of foreign elements, for example, after carbonization. Graphitization can also be carried out by heating to $\mathrm{T} \sim 1200 \mathrm{~K}$. The carbon content of the residue exceeds a mass fraction of $90 \mathrm{wt} . \%$, while at $\mathrm{T} \sim 1600 \mathrm{~K}$ more than 99 wt.\% carbon can be found [37].

For some defined applications, organic or inorganic particles are added to polymer solutions [38], for example to improve the mechanical properties.

The addition of nanoparticles to PAN electrospinning solutions can, e.g., be used to produce magnetic PAN nanofiber mats. Many materials have magnetic properties, including iron [39], manganese alloys, magnetite [40] or cobalt. Sometimes magnetism is not the primary use of magnetic nanofibers, but the magnetic material can perform other functions. Recently, Wang et al. [41] manufactured $\mathrm{CuFe}_{2} \mathrm{O}_{4}$ fibers in which they were able to adjust the amount of $\mathrm{CuO}$ nanoparticles on the surface of the fibers by changing the ratio between the precursor of $\mathrm{Co}$ and that of $\mathrm{Fe}$, thus making these fibers usable for catalytic oxidation [42]. These materials can exist as permanent magnets or be paramagnetic. This means they can be attracted by magnetic materials but not have permanent magnetism themselves. 
Ferrite nanoparticles or iron oxide nanoparticles (iron oxides in the crystal structure of maghemite or magnetite) are the most commonly used magnetic nanoparticles. According to the literature, the magnetic nanoparticles become superparamagnetic when the ferrite particles become smaller than about $128 \mathrm{~nm}$ [43]. This prevents self-agglomeration to a certain amount because they only show their magnetic behavior when an external magnetic field is applied. Wortmann et al. [44] have examined magnetic nanofiber mats using transmission electron microscopy (TEM) and nevertheless found agglomeration of magnetic nanoparticles in nanofibers. The goal of this study is to further explore whether it is possible to detect these agglomerations in a different way without using a lengthy and expensive methods such as TEM.

\section{Materials and methods}

The nanofiber mats were prepared using polyacrylonitrile (PAN) (X-PAN, Dralon, Dormagen, Germany; $M_{n}=90,000 \mathrm{~g} / \mathrm{ml}, M_{w}=250,000 \mathrm{~g} / \mathrm{mol}$ ) dissolved in DMSO (min. 99.9\%, obtained from S3 chemicals, Bad Oeynhausen, Germany). The ratio of $14 \%$ PAN with magnetic particles in DMSO proved to be the best ratio according to a previous study [45]. The polymer:nanoparticle weight ratio of 1:1.8 has given the highest nanoparticle concentration [45]. For the preparation of pure PAN nanofibers without beads, the ratio of $16 \%$ PAN in DMSO was found to be the most suitable [35]. As substrate, a polypropylene (PP) nonwoven (Elmarco, Czech Republic) was used as a supporting layer for collecting nanofibers.

All polymer solutions were stirred for $2 \mathrm{~h}$ on a magnetic stirrer. Afterwards, magnetic nanoparticles were incorporated, i.e. $\mathrm{Fe}_{3} \mathrm{O}_{4}$ (magnetite) with a particle size of $50-100 \mathrm{~nm}$ and $\mathrm{Fe}_{2} \mathrm{O}_{3} / \mathrm{NiO}$ (diiron nickel tetroxide) with a particle size < $50 \mathrm{~nm}$ (both purchased from Merck KGA, Darmstadt, Germany). The solution was then mixed manually for 10 minutes before the nanoparticles were dispersed in an ultrasonic bath for 40 minutes at $35{ }^{\circ} \mathrm{C}$ and a frequency of $37 \mathrm{kHz}$. The mixing and homogenization condition were selected based on the results of the previous study [45].

A wire-based electrospinning machine "Nanospider Lab" (Elmarco, Czech Republic) was used to produce nanofibers. This machine is easy to operate, which makes it ideal for lab-scale work. The Nanospider can spin a variety of polymers, and one of its advantages is that little polymer solution can be used to prepare nanofiber mats on a large scale. The following spinning parameters were used: high voltage $80 \mathrm{kV}$, nozzle diameter $0.9 \mathrm{~mm}$, carriage speed $150 \mathrm{~mm} / \mathrm{s}$, electrode-substrate distance $240 \mathrm{~mm}$, bottom-substrate distance $50 \mathrm{~mm}$, temperature in the chamber was $22^{\circ} \mathrm{C}$ and relative humidity in the chamber was $32 \%$. A spinning solution of $5 \mathrm{~mL}$ was used in all tests and spun during $\sim 15 \mathrm{~min}$.

Oxidative stabilization of nanofiber mats was carried out in an oven (Nabertherm, Lilienthal, Germany) approaching a typical stabilization temperature of $280{ }^{\circ} \mathrm{C}$ with a heating rate of $1 \mathrm{~K} / \mathrm{min}$, followed by isothermal treatment at this temperature for 1 hour. For the carbonization process, a furnace (Carbolite Gero, Neuhausen, Germany) was chosen to approach a temperature of $500{ }^{\circ} \mathrm{C}$ with a heating rate of $10 \mathrm{~K} / \mathrm{min}$ in a nitrogen flow of $150 \mathrm{~mL} / \mathrm{min}$ (STP), followed by isothermal treatment at the final temperature for 1 hour.

A Zeiss 1450VPSE scanning electron microscope (SEM) and a VK-8710 confocal laser scanning microscope (CLSM) (Keyence) were used for optical surface analysis of the nanofiber mats. To investigate the chemical composition of the samples, energy-dispersive X-ray spectroscopy (EDS) was used for more detailed investigations. The samples were sputtered with $20 \mathrm{~nm}$ of gold to avoid charging them. Table 1 shows the samples that were prepared.

Table1: Overview of the samples

\begin{tabular}{l}
\hline $16 \%$ PAN \\
\hline $14 \%$ PAN/magnetite \\
\hline $14 \%$ PAN/diiron nickel tetroxide \\
\hline
\end{tabular}




\section{Result and discussion}

The morphologies of the studied nanofiber mats are shown in the CLSM images in Figure 1. For the three samples (electrospun, stabilized and carbonized), the images are very similar, showing a relatively regular nanofiber mat with some fine fibers, but they have different colors due to the heat treatment processes. The fibers show a light brown discoloration during stabilization (Fig. 1b) and a more black discoloration when carbonization starts (Fig. 1c), differences which are easily recognizable. The heat treatment at $500{ }^{\circ} \mathrm{C}$ does not complete carbonization and therefore dark brown color is still clearly visible in the carbonized sample (Fig. 1c). In case of complete carbonization at $800^{\circ} \mathrm{C}$, the CLSM images show rather black color without brown parts [21]. CLSM images allow seeing a strong bead formation, but it is not possible to see if there are agglomerations of magnetic particles.

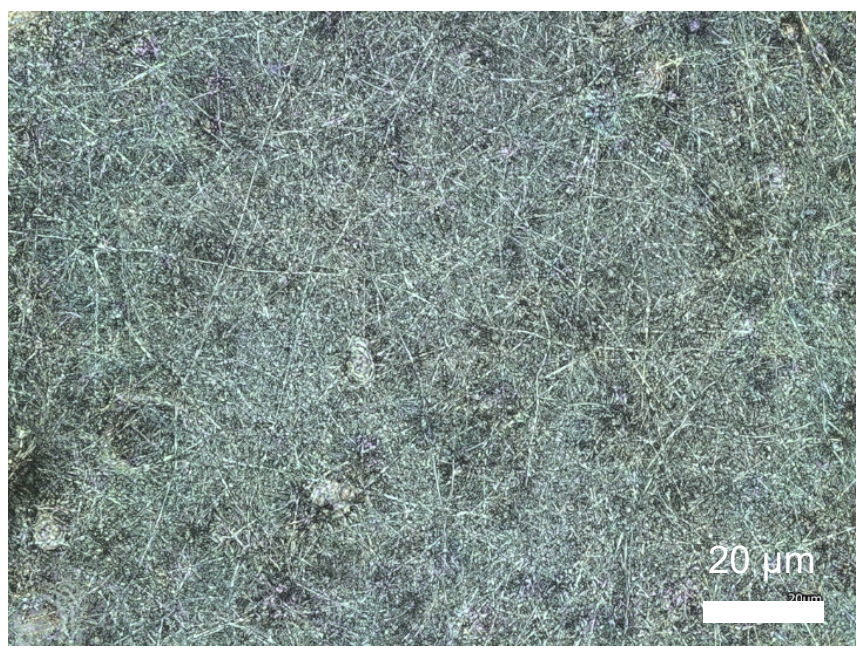

(a)

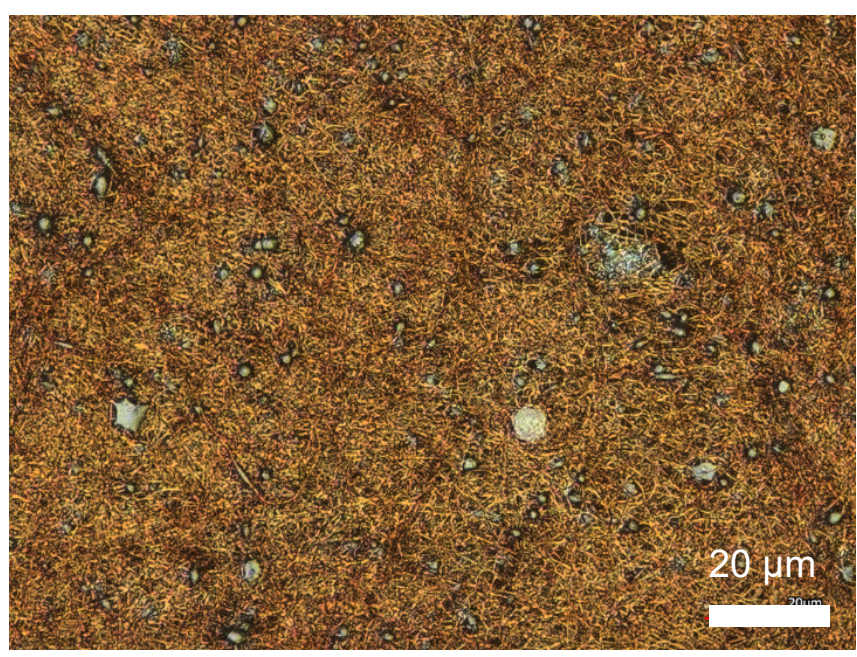

(b)

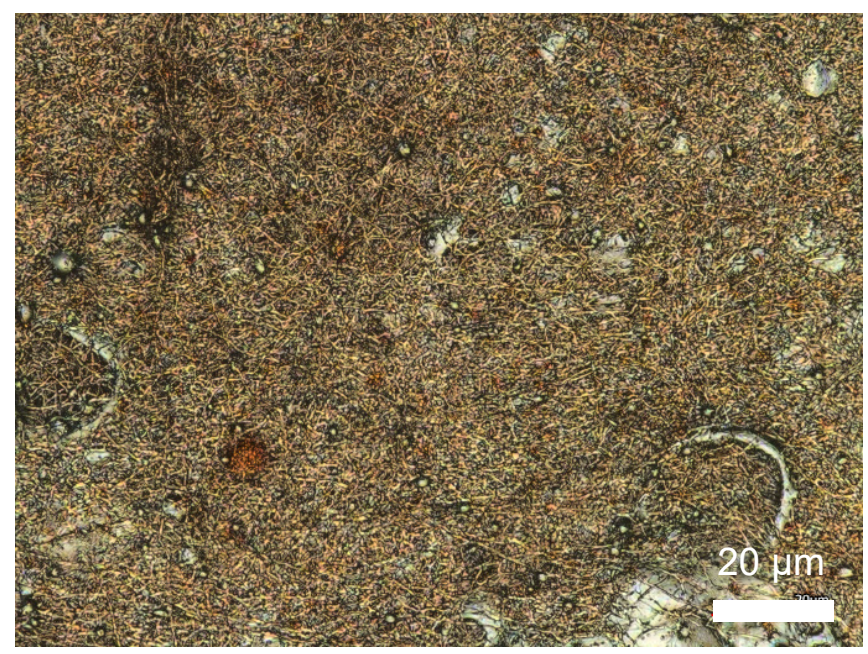

(c)

Fig 1 CLSM images of (a) PAN/magnetite after electrospinning; (b) stabilized; and (c) carbonized at $500{ }^{\circ} \mathrm{C}$.

With optical methods it is difficult to detect agglomerations in the nanofibers. Thus, possible agglomerations of magnetic nanoparticles cannot be seen in the CLSM images (Fig. 1).

Figure 2 shows SEM images of the nanofiber mats obtained from $\mathrm{PAN} / \mathrm{Fe}_{2} \mathrm{O}_{3} / \mathrm{NiO}$ (iron nickel tetroxide) samples. After electrospinning, the nanofibers are almost straight, smooth and randomly oriented (cf. Fig. 2a). The stabilized (Fig. 2b) and carbonized (Fig. 2c) samples change their surface morphology. The nanofibers get curved and change their dimensions due to the influence of the heat treatment process. This occurs because of carbon chains that are highly flexible due to rotation around carbon-carbon single bond, allowing the molecules to take up many different configurations. 


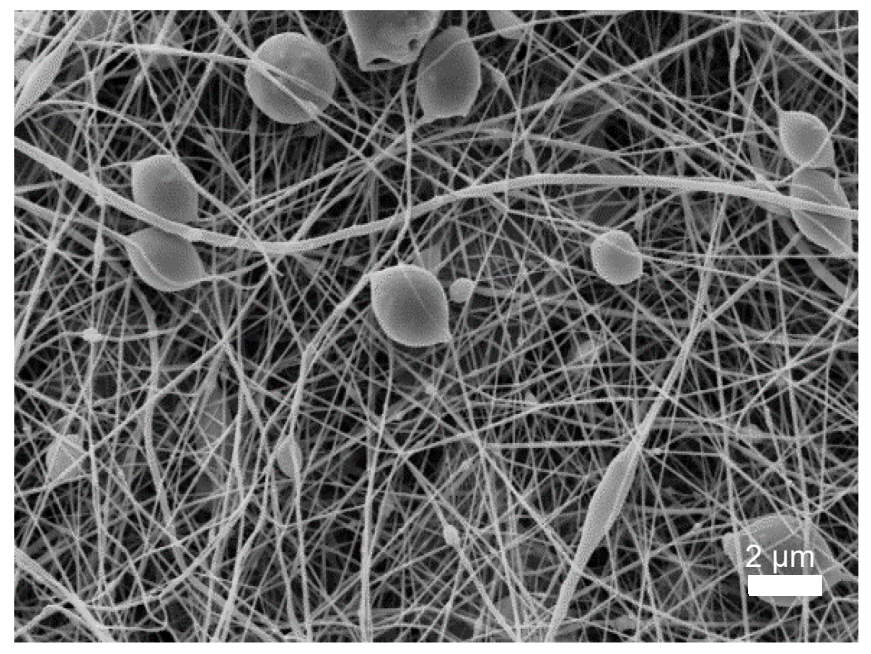

(a)

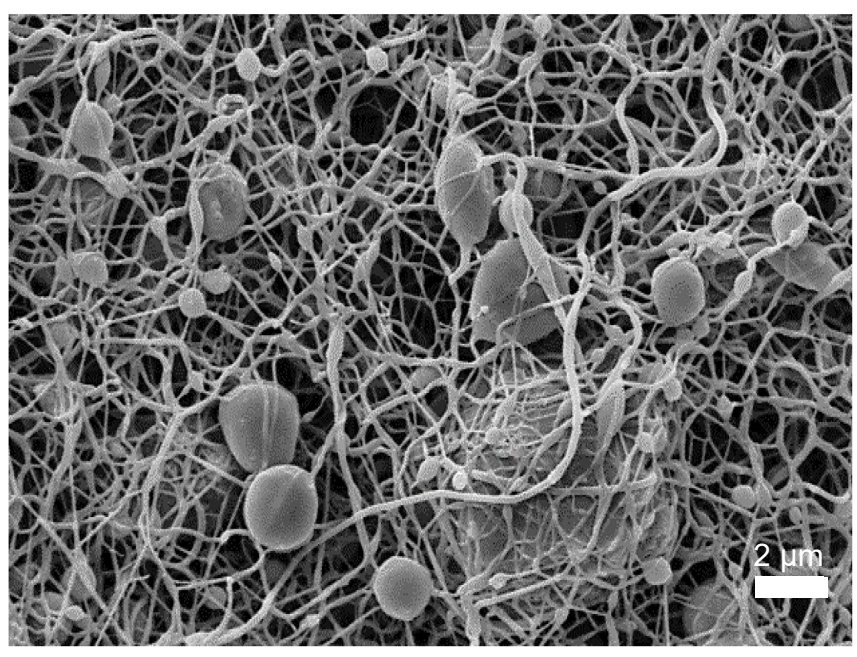

(b)

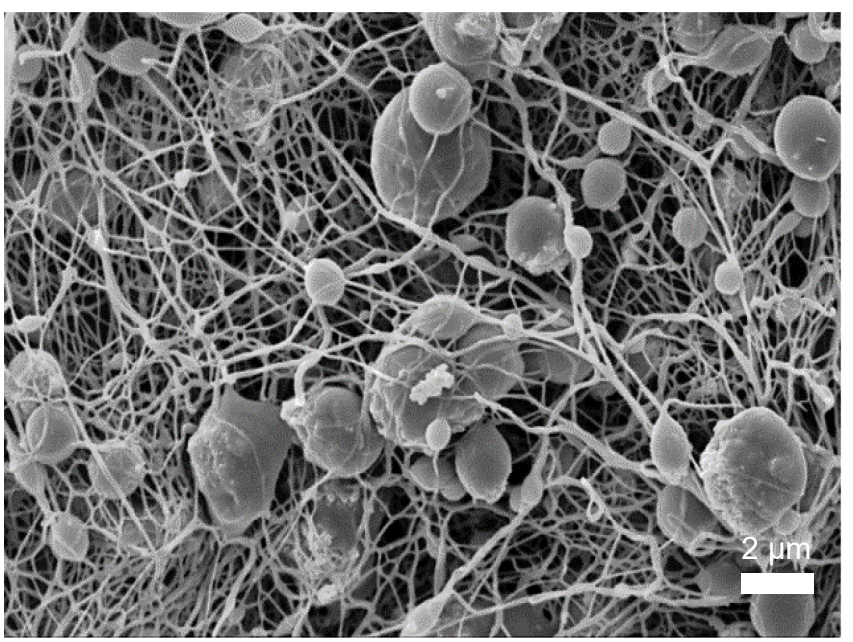

(c)

Fig. 2 SEM images of PAN/ diiron nickel tetroxide with a nominal magnification of $5000 x$, (a) after electrospinning; (b) stabilized; and (c) carbonized. (a) and (b) reproduced from [46], published under a CC BY 4.0 license.

Figure 3 shows SEM images comparing pure PAN (3a) and PAN/magnetite (3b) after electrospinning.

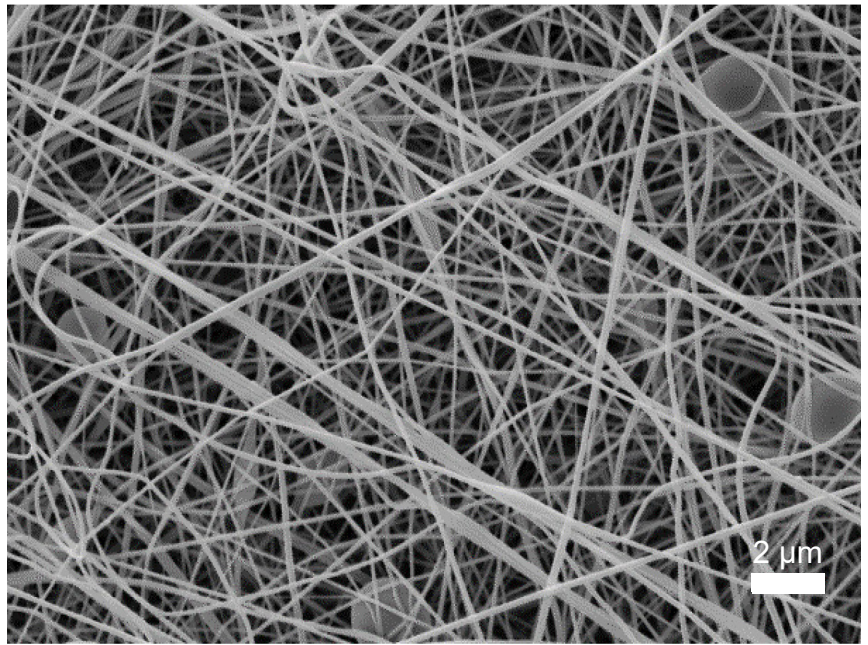

(a)

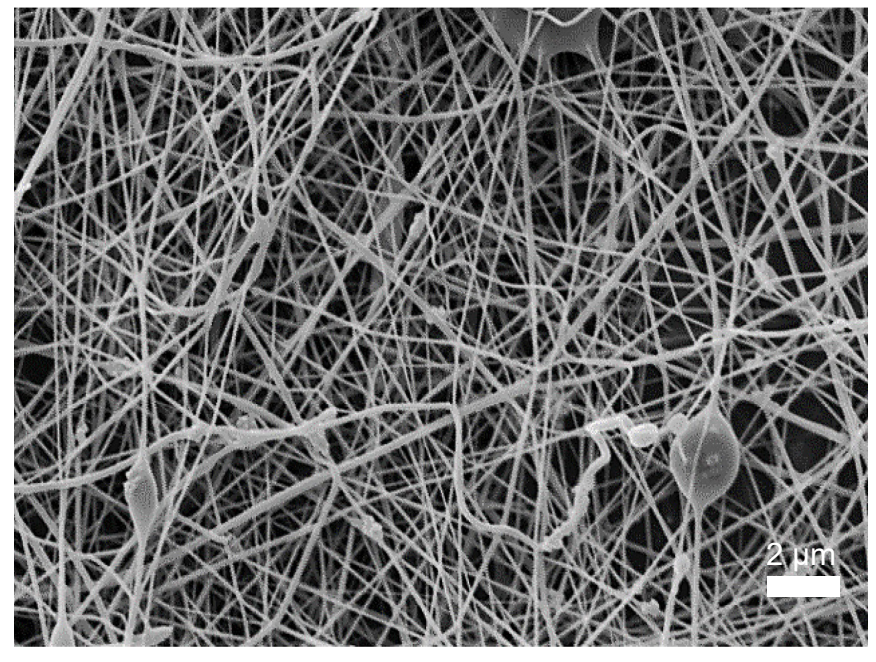

(b)

Fig. 3 SEM images of (a) pure PAN and (b) PAN/magnetite nanofiber mats, taken with a nominal magnification of $5000 \times$ after the electrospinning process. 
In pure PAN nanofibers (Fig. 3a), the nanofibers show more relatively straight orientation compared to PAN/diiron nickel tetroxide (Fig. 2a) and PAN/magnetite (Fig. 3b). In all three as-spun nanofiber mats, some nanofibers are connected with some beads and the most beads can be seen on the surface of PAN/diiron nickel tetroxide (Fig. 2a). In addition, the beads look slightly rough and a bit different from PAN/magnetite nanofibers (Fig. 3b), which can be explained by the fact that the diiron nickel tetroxide nanoparticles are concentrated in the beads due to their small size, as found later in the EDS spectra.

When particles are added to the nanofiber mats, the fiber diameters change. The distributions of nanofiber diameters are shown in Figure 4.

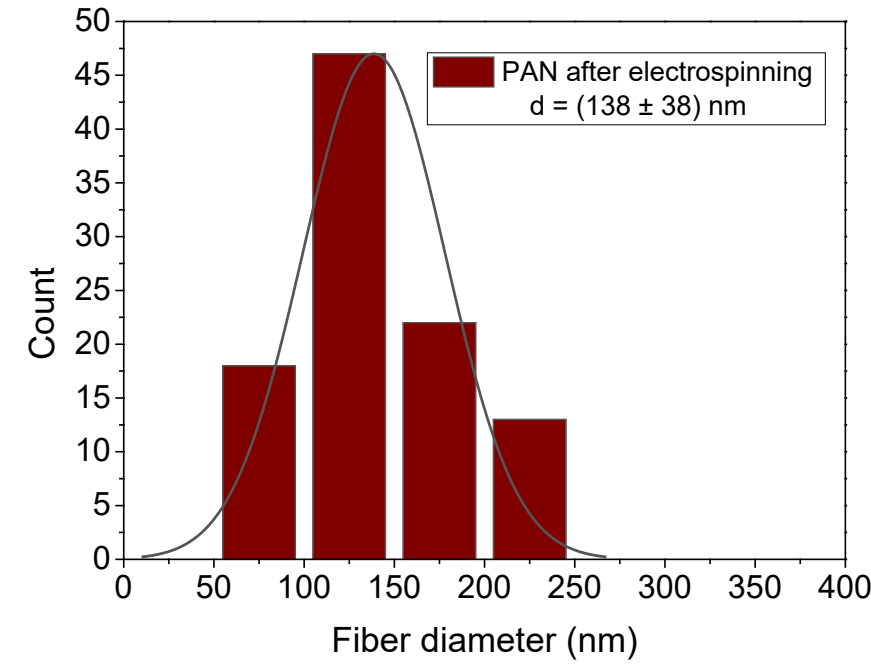

(a)

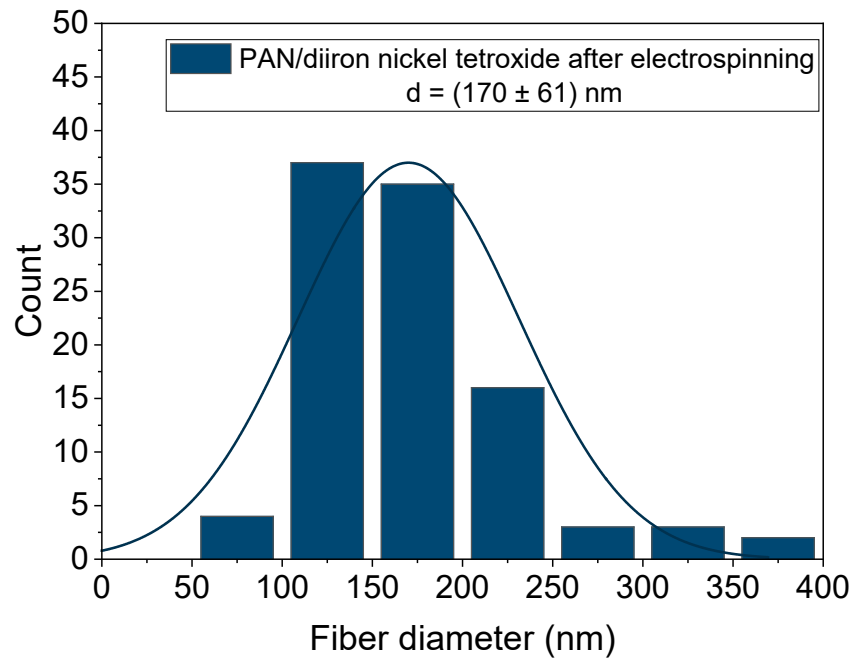

(b)

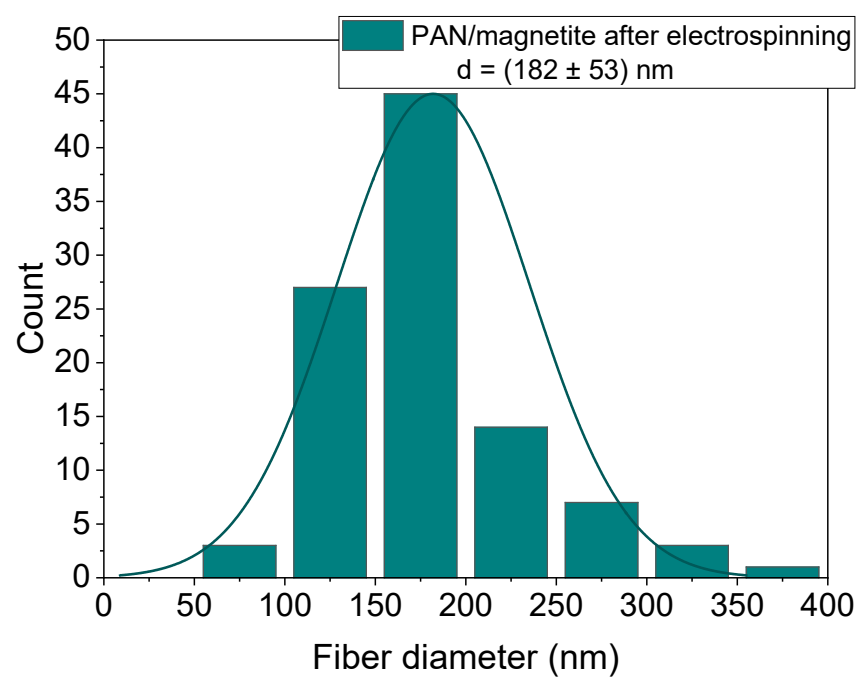

(c)

Fig. 4 Distributions of the diameters of: (a) PAN nanofibers; (b) PAN/diiron nickel tetroxide nanofibers;

(c) PAN/magnetite nanofibers.

Both PAN/magnetite $((182 \pm 53) \mathrm{nm})$ and PAN/diiron nickel tetroxide $((170 \pm 61) \mathrm{nm})$ nanofiber mats show a higher average as well as a wider distribution of nanofiber diameters compared to pure PAN (cf. Figures $4 \mathrm{~b}$ and 4c). Correspondingly, pure PAN nanofiber mats (4a) exhibit a lower average $((138 \pm 38) \mathrm{nm})$ as well as a narrower distribution of nanofiber diameters. In addition, the PAN/magnetite nanofiber (4c) show a slightly larger average than PAN/diiron nickel tetroxide (4b) nanofiber mats. 
For a closer investigation, Figure 5 depicts the surface scanned with EDS and the spectra of the materials inside this surface. The EDS spectrum was obtained in a microscopic area of the sample. As a result, the presence of carbon $(\mathrm{C})$ in a large amount at $0.3 \mathrm{keV}$ due to the heat treatment process and peaks at $0.5 \mathrm{keV}, 6.4 \mathrm{keV}$ and $7.1 \mathrm{keV}$ related to iron (Fe) can be detected. In addition, the peaks at $0.7 \mathrm{keV}, 0.8 \mathrm{keV}$ and $7.5 \mathrm{keV}$ confirm the existence of nickel $(\mathrm{Ni})$.

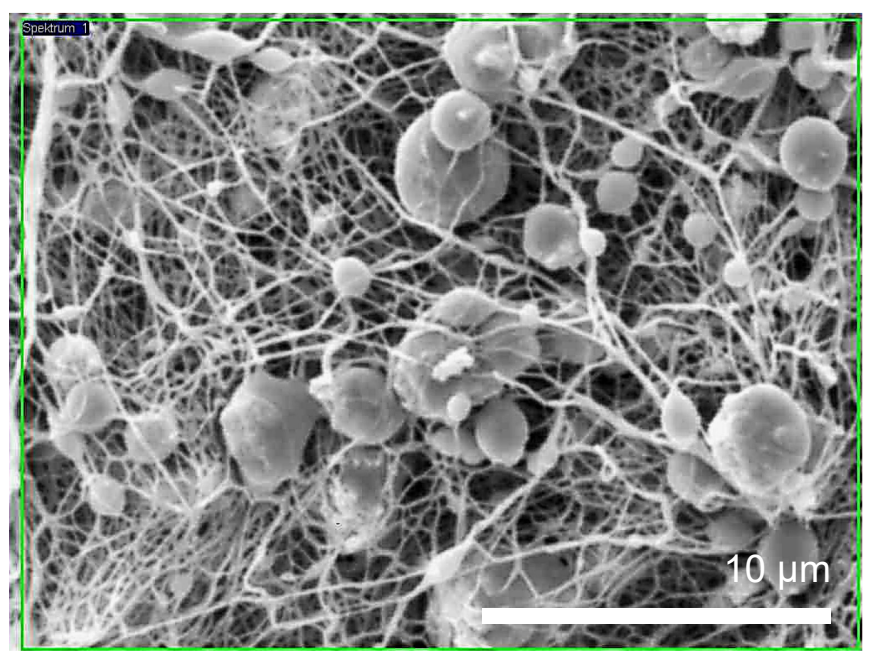

(a)

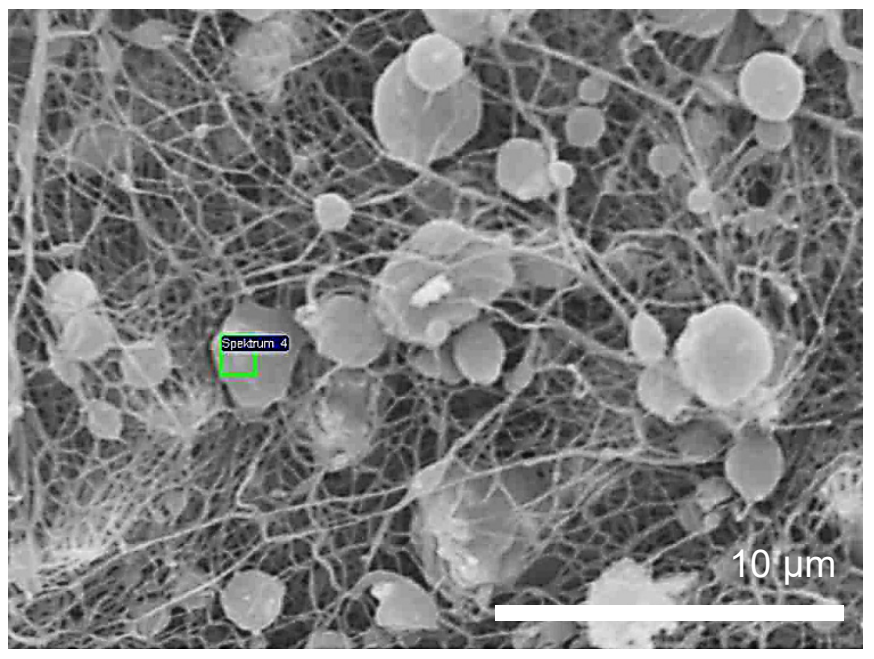

(b)

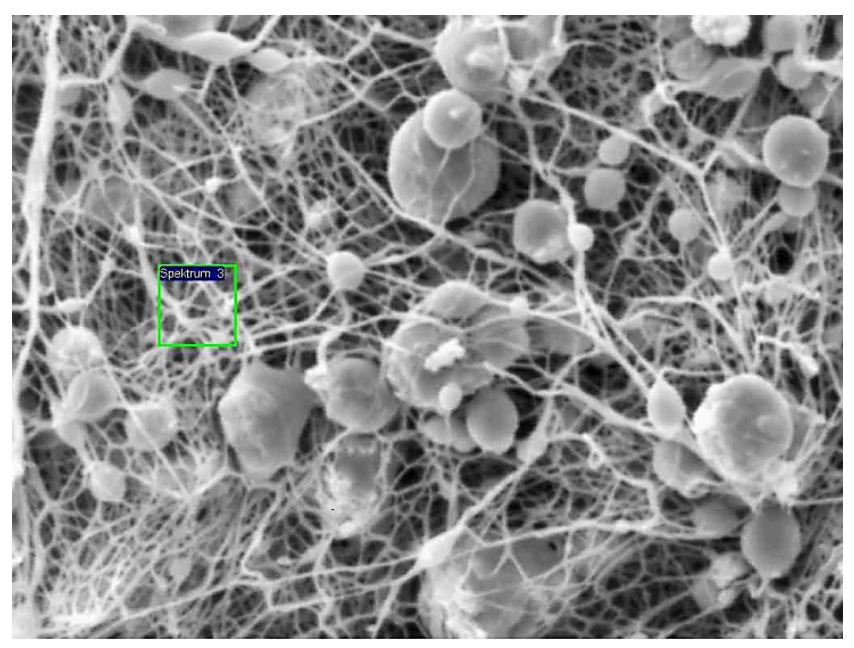

(c)

Fig. 5 SEM images of carbonized PAN/diiron nickel tetroxide sample (a) whole surface, (b) spot on a bead; and (c) spot on a nanofibers.

As can be seen in the sub-images in Figure 5, the examined areas are marked with a green frame, and the EDS spectra are created for these areas. For the comparison of the magnetic samples, the gold peak is set as a reference in the EDS spectrum and is marked by a blue arrow (see Figures 6 a-c). The first EDS spectrum (Fig. 6a) defines the complete area of the nanofiber mat and the second (Fig. 6b) only a small area where a bead is located. A measurement of an area with fibers only is shown in Figure 6c. The iron peak ( $\mathrm{Fe}$ ) shown by the red arrow in the first EDS spectrum (Fig. 6a) is lower than the iron peak in Figure 6b. Similarly, the nickel peak (Ni) in Figure $6 \mathrm{~b}$ is much higher than in Figure 6a and 6c. It can be noted that Figure $6 c$ shows a significant difference from the maps with the beads (Fig. $6 b$ ), i.e. here the iron peak $(\mathrm{Fe})$ is even lower than in the overall map (cf. Figure 6a). 


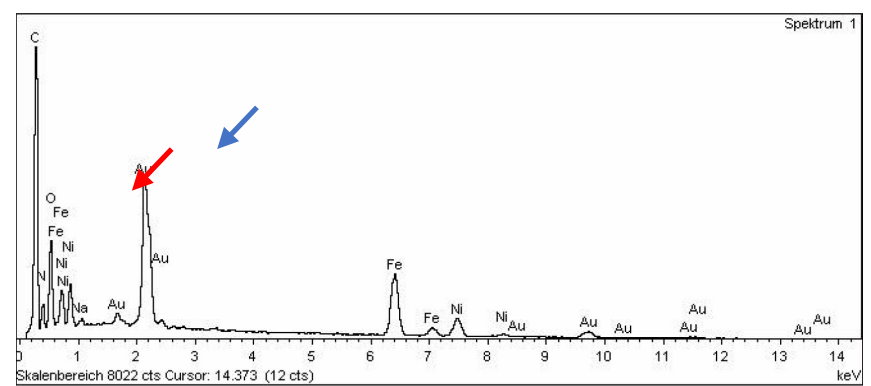

(a)

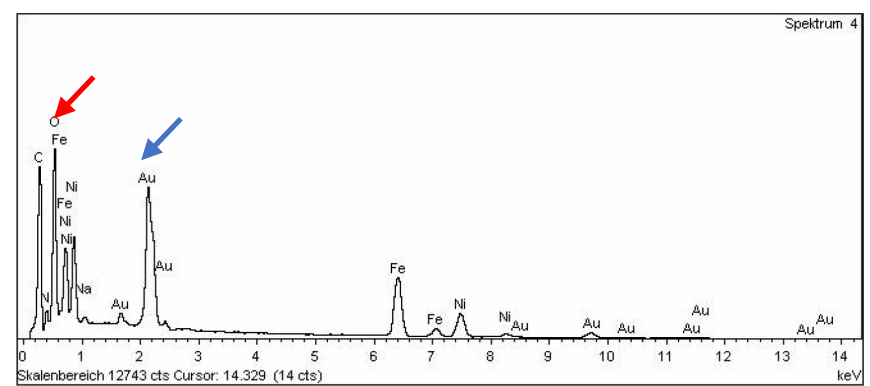

(b)

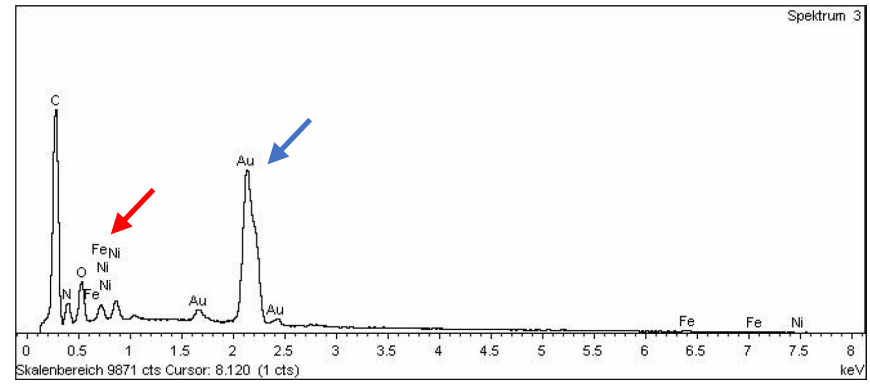

(c)

Fig. 6: EDS spectrum of carbonized PAN/diiron nickel tetroxide sample: (a) whole surface; (b) spot on a bead; and (c) spot on nanofibers.

This suggests that the highest concentration of particles is located in the beads. Moreover, the EDS spectrum shows strong peaks of iron $(\mathrm{Fe})$ and nickel $(\mathrm{Ni})$ elements, which are significantly more abundant than carbon $(\mathrm{C})$, confirming that the diiron nickel tetroxide nanoparticles are agglomerated within the beads.

Nanofibers or nanoparticles are certainly not the only areas of materials science in which such fundamental structural problems as agglomerations can occur. Thus, tests such as TEM analysis can be avoided when EDS is used to determine where possible agglomerations are located. TEM needs long and complex preparations, therefore it is very helpful that the agglomerates are also clearly visible in EDS. Nanofibers are used here as a substitute for practically all types of micro- and nanomaterials that are tested using microscopic images at high magnification. There are, of course, samples whose structures in question cannot be displayed at a lower magnification (such as atomic structures).

\section{Conclusions}

In this study, PAN/magnetic nanofibers were produced and investigated from a DMSO polymer solution using a wire-based electrospinning process. The chemical and morphological properties of the magnetic nanofibers after the heat treatment steps were examined using various characterization methods. The preparation of the samples and the acquisition of high-resolution images, for example for TEM examinations, require a lot of time and intensive preparation. For this reason, this study looked for a simpler way to find out whether nanoparticle agglomerations in the nanofibers occur, without using TEM. The results of this study lead to the conclusion that the EDS is a simpler, better manageable and more efficient technique that does not require much time to investigate the presence of agglomerations of nanoparticles in nanofiber mats.

\section{Acknowledgements}

The study was partly funded by the Erasmus+ program of the European Union. 


\section{References}

[1] D. Yadav, F. Amini, A. Ehrmann. 2020. Recent advances in carbon nanofibers and their applications - A review. Eur.Polym. J. 138,109963. DOI: https://doi.org/10.1016/j.eurpolymj.2020.109963.

[2] F. E. C. Othman, N. Yusof, H. Hasbullah, J. Jaafar, A. F. Ismail, N. Abdullah, N. A. H. M. Nordin, F. Aziz, W. N. W. Salleh. 2017. Polyacrylonitrile/magnesium oxide-based activated carbon nanofibers with well-developed microporous structure and their adsorption performance for methane. J. Ind. Eng. Chem. 51, 281-287. DOI: https://doi.org/10.1063/5.0008012.

[3] I. Latsunskyi, A. Vasylenko, R. Viter, M. Kempinski, G. Mowaczyk, S. Jurga, M. Bechelany. 2017. Tailoring of the electronic properties of ZnO-polyacrylonitrile nanofibers, Experiment and theory. Appl. Surf. Sci. 411, 494-501. DOI: https://doi.org/10.1016/j.apsusc.2017.03.111.

[4] H. T. Niu, X. G. Wang, T. Lin. 2012. Upward Needleless Electrospinning of Nanofibers. J. Eng. Fibers Fabr. 7, 17-22. DOI: https://doi.org/10.1177/155892501200702S03.

[5] S. V. Lomos, K. Molnar. 2016. Compressibility of carbon fabrics with needleless electrospun PAN nanofibrous interleaves. Express Polym. Lett. 10, 25-35. DOI: 10.3144/expresspolymlett.2016.

[6] J. N. Zhang, M. Y. Song, D. W. Li, Z. P. Yang, J. H. Cao, Y. Chen, Y. Xu, Q. F. Wei. 2016. Preparation of selfclustering highly oriented nanofibers by needleless electrospinning methods. Fibers Polym. 17, 1414-1420. DOI: https://doi.org/10.1007/s12221-016-6581-x.

[7] T. Grothe, J. Brikmann, H. Meissner, A. Ehrmann. 2017. Influence of solution and spinning parameters on nanofiber mat creation of poly(ethylene oxide) by needleless electrospinning. Mater. Sci. 23, 342-349. DOI: 10.5755/j01.ms.23.4.17169.

[8] H. Fong, I. Chun, D. H. Reneker. 1999. Beaded nanofibers formed during electrospinning. Polymer 40, 45854592. DOI: https://doi.org/10.1016/S0032-3861(99)00068-3.

[9] N. Haitao, L. Tong. 2012. Fiber generators in needleless electrospinning. J. Nanomater. 2012, 725950. DOI: https://doi.org/10.1155/2012/725950.

[10] M. Zahmatkeshan, M. Adel, S. Bahrami, F. Esmaeli, S. M. Rezayat, Y. Saeedi, B. Mehravi, S. B. Jameie, K. Ashtari. 2018. Polymer Based Nanofibers: Preparation, Fabrication, and Applications. In: A. Barhoum, M. Bechelany, A. Makhlouf (Eds.) Handbook of Nanofibers. Springer, Cham. DOI: https://doi.org/10.1007/978-3-31942789-8_29-2.

[11] J. Kaur, K. Millington, S. Smith. 2016. Producing high-quality precursor polymer and fibers to achieve theoretical strength in carbon fibers: A review. J. Appl. Polym. Sci. 133, 43963. DOI: https://doi.org/10.1002/app.43963.

[12] S. Megelski, J. S. Stephens, D. B. Chase, J. F. Rabolt. 2002. Micro- and nanostructured surface morphology on electrospun polymer fibers. Macromolecules 35, 22, 8456-8466. DOI: https://doi.org/10.1021/ma020444a.

[13] L. Sabantina, M. Klöcker, M. Wortmann, J. Rodríguez Mirasol, T. Cordero, E. Moritzer, K. Finsterbusch, A. Ehrmann. 2020. Stabilization of polyacrylonitrile nanofiber mats obtained by needleless electrospinning using dimethyl sulfoxide as solvent. J. Ind. Text. 50, 2, 224-239. DOI: https://doi.org/10.1177/1528083718825315.

[14] A. Zulfi, D. A. Hapidin, M. M. Munir, F. Iskandar, K. Khairurrijal. 2019. The synthesis of nanofiber membranes from acrylonitrile butadiene styrene (ABS) waste using electrospinning for use as air filtration media. RSC Adv. 9, 30741. DOI: https://doi.org/10.1039/C9RA04877D.

[15] Q. Y. Wu, X. N. Chen, L. S. Wan, Z. K. Xu. 2012. Interactions between polyacrylonitrile and solvents: Density functional theory study and two-dimensional infrared correlation analysis. J. Phys. Chem. B 116, 28, 8321-8330. DOI: https://doi.org/10.1021/jp304167f.

[16] M. Hattori, H. Yamazaki, M. Saito, K. Hisatani, K. Okajima. 1996. NMR study on the dissolved state of polyacrylonitrile in various solvents. Polym. J. 28, 594-600. DOI: https://doi.org/10.1295/polymj.28.594.

[17] A. Khajuria, P. N. Balaguru. Plastic shrinkage characteristics of fiber reinforced cement composites. 1992. In: R. N. Swamy (Ed.), Fibre reinforced Cement and Concrete: Proceedings of the Fourth RILEM International Symposium, 82-90.

[18] M. M. Lovleva, V. N. Smirnova, G. A. Budnitskii. 2001. The solubility of polyacrylonitrile. Fibre Chem. 33, 262264. DOI: https://doi.org/10.1023/A:1012934313303.

[19] T. Marino, S. Blefari, E. Di Nicolò, A. Figoli. 2017. A more sustainable membrane preparation using triethyl phosphate as solvent. Green Process. Synth. 6, 3, 295-300. DOI: https://doi.org/10.1515/gps-2016-0165.

[20] L. Sabantina, J. R. Mirasol, T. Cordero, K. Finsterbusch, A. Ehrmann. 2018. Investigation of needleless electrospun PAN nanofiber mats. AIP Conf. Proc. 1952, 020085. DOI: https://doi.org/10.1063/1.5032047.

[21] L. Sabantina, M. A. Rodríguez-Cano, M. Klöcker, F. J. García-Mateos, J. J. Ternero-Hidalgo, A. Mamun, F. Beermann, M. Schwakenberg, A.-L. Voigt, J. Rodríguez Mirasol, T. Cordero, A. Ehrmann. 2018. Fixing PAN nanofiber mats during stabilization for carbonization and creating novel metal/carbon composites. Polymers 10, 735. DOI: https://doi.org/10.3390/polym10070735.

[22] S. M. Lemma, A. Esposito, M. Mason, L. Brusetti, S. Cesco, M. Scampicchio. 2015. Removal of bacteria and yeast in water and beer by nylon nanofibrous membranes. J. Food Eng. 157, 1-6. DOI: https://doi.org/10.1016/j.jfoodeng.2015.02.005. 
[23] R. Roche, F. Yalcinkaya. 2019. Electrospun polyacrylonitrile nanofibrous membranes for point-of-use water and air cleaning. ChemistryOpen 8, 97-103. DOI: https://doi.org/10.1002/open.201800267.

[24] R. Ruiz-Rosas, J. M. Rosas, I. G. Loscertales, J. Rodríguez-Mirasol, T. Cordero. 2014. Electrospinning of silica sub-microtubes mats with platinum nanoparticles for NO catalytic reduction. Appl. Catal. B Environ. 156-157, 1524. DOI: https://doi.org/10.1016/j.apcatb.2014.02.047.

[25] F. J. García-Mateos, R. Berenguer, M. J. Valero-Romero, J. Rodríguez-Mirasol, T. Cordero. 2018. Phosphorus functionalization for the rapid preparation of highly nanoporous submicron-diameter carbon fibers by electrospinning of lignin solutions. J. Mater. Chem. A 6, 1219-1233. DOI: https://doi.org/10.1039/C7TA08788H.

[26] N. Ashammakhi, A. Ndreu, Y. Yang, H. Ylikauppila, L. Nikkola. 2012. Nanofiber-based scaffolds for tissue engineering. Eur. J. Plast. Surg. 35, 135-149. DOI: https://doi.org/10.1007/s00238-008-0217-3.

[27] D. Wehlage, H. Blattner, L. Sabantina, R. Böttjer, T. Grothe, A. Rattenholl, F. Gudermann, D. Lütkemeyer, A. Ehrmann. 2019. Sterilization of PAN/gelatine nanofibrous mats for cell growth. Tekstilec 62, 78-88. DOI: https://doi.org/10.14502/Tekstilec2019.62.78-88.

[28] A. Mamun. 2019. Review of possible applications of nanofibrous mats for wound dressings. Tekstilec 62, 89100. DOI: https://doi.org/10.14502/Tekstilec2019.62.89-100.

[29] E. Cipriani, M. Zanetti, P. Bracco, V. Brunella, M. P. Luda, L. Costa. 2016. Crosslinking and carbonization processes in PAN films and nanofibers. Polym. Degrad. Stab. 123, 178-188. DOI: https://doi.org/10.1016/j.polymdegradstab.2015.11.008.

[30] Z. Z. Zhao, J. Q. Li, X. Y. Yuan, X. Li, Y. Y. Zhang, J. Sheng. 2005. Preparation and properties of electrospun poly(vinylidene fluoride) membranes. J. Appl. Polym. Sci. 97, 466-474. DOI: https://doi.org/10.1002/app.21762.

[31] T. H. Ko. 1991. The influence of pyrolysis on physical properties and microstructure of modified PAN fibers during carbonization. Appl. Polym. Sci. 43, 589-600. DOI: https://doi.org/10.1002/app.1991.070430321.

[32] A. Shokuhfar, A. Sedghi, R. E. Farsani. 2013. Effect of thermal characteristics of commercial and special polyacrylonitrile fibres on the fabrication of carbon fibres. Mater. Sci. Technol. 22, 1235-1239. DOI: https://doi.org/10.1179/174328406X129887.

[33] N. Yusof, A. F. Ismail. 2011. Post spinning and pyrolysis processes of polyacrylonitrile (PAN)-based carbon fiber and activated carbon fiber: A review. J. Anal. Appl. Pyrolysis 93, 1-13. DOI: https://doi.org/10.1016/j.jaap.2011.10.001.

[34] J. L. Storck, B. Brockhagen, T. Grothe, L. Sabantina, K. Kaltschmidt, H. Tuvshinbayar, L. Braun, E. Tanzli, A. Hütten, A. Ehrmann. 2021. Stabilization and carbonization of PAN nanofiber mats electrospun on metal substrates. C - Journal of Carbon Research 7, 12. DOI: https://doi.org/10.3390/c7010012.

[35] D. Wehlage, R. Böttjer, T. Grothe, A. Ehrmann. 2018. Electrospinning water-soluble/insoluble polymer blends. AIMS Mater. Sci. 5, 2, 190-200. DOI: https://doi.org/10.3934/matersci.2018.2.190.

[36] J. L. Storck, T. Grothe, K. Tuvshinbayar, E. Diestelhorst, D. Wehlage, B. Brockhagen, M. Wortmann, N. Frese, A. Ehrmann. 2020. Stabilization and incipient carbonization of electrospun polyacrylonitrile nanofibers fixated on aluminum substrates. Fibers 8, 55. DOI: https://doi.org/10.3390/fib8090055.

[37] H. Marsh, F. Rodríguez-Reinoso. 2006. Activated carbon (1 ${ }^{\text {st }}$ ed.). Elsevier Science, Amsterdam, Netherlands. DOI: https://doi.org/10.1016/B978-0-08-044463-5.X5013-4.

[38] U. Adhikari, X. An, N. Rijal, T. Hopkins, S. Khanal, T. Chavez, R. Tatu, J. Sankar, K. L. Little, D. B. Hom, N. Bhattarai, S. K. Pixley. 2019. Embedding magnesium metallic particles in polycaprolactone nanofiber mesh improves applicability for biomedical applications. Acta Biomater. 98, 215-234. DOI: https://doi.org/10.1016/j.actbio.2019.04.061.

[39] D. Sudsom, A. Ehrmann. 2021. Micromagnetic simulations of $\mathrm{Fe}$ and Ni nanodot arrays surrounded by magnetic or non-magnetic matrices. Nanomater. 11, 349. DOI: https://doi.org/10.3390/nano11020349.

[40] T. Blachowicz, A. Ehrmann. 2021. Influence of clustering round magnetic nano-dots on magnetization reversal. J. Phys. Conf. Series 1730, 012034. DOI: https://doi.org/10.1088/1742-6596/1730/1/012034.

[41] P. Wang, T. Dong, M. Li, P. Yang. 2019. Controlling growth of $\mathrm{CuO}$ nanoparticles on $\mathrm{CuFe}_{2} \mathrm{O}_{4}$ nanotubes and their adsorption kinetics. J. Nanosci. Nanotechnol. 19, 8, 4474-4480. DOI: https://doi.org/10.1166/jnn.2019.16481.

[42] T. Blachowicz, A. Ehrmann. 2020. Most recent developments in electrospun magnetic nanofibers: A review. J. Eng. Fibers Fabr. 15, 1558925019900843. DOI: https://doi.org/10.1177/1558925019900843.

[43] A. H. Lu, E. L. Salabas, F. Schüth. 2007. Magnetic nanoparticles: synthesis, protection, functionalization, and application. Angew. Chem. Int. Ed. 46, 1222-1244. DOI: https://doi.org/10.1002/anie.200602866.

[44] M. Wortmann, A. S. Layland, N. Frese, U. Kahmann, T. Grothe, J. L. Storck, T. Blachowicz, J. Grzybowski, B. Hüsgen, A. Ehrmann. 2020. On the reliability of highly magnified micrographs for structural analysis in materials science. Sci. Rep. 10, 14708. DOI: https://doi.org/10.1038/s41598-020-71682-8.

[45] C. Döpke, T. Grothe, P. Steblinski, M. Klöcker, L. Sabantina, D. Kosmalska, T. Blachowicz, A. Ehrmann. 2019. Magnetic nanofiber mats for data storage and transfer. Nanomater. 9, 92. DOI: https://doi.org/10.3390/nano9010092.

[46] N. Fokin, T. Grothe, A. Mamun, M. Trabelsi, M. Klöcker, L. Sabantina, C. Döpke, T. Blachowicz, A. Hütten, A. Ehrmann. 2020. Magnetic properties of electrospun magnetic nanofiber mats after stabilization and carbonization. Materials 13, 1552. DOI: https://doi.org/10.3390/ma13071552. 